\title{
Spatio-Temporal Distribution and Fixed-Precision Sampling Plan of Scirtothrips dorsalis (Thysanoptera: Thripidae) in Florida Blueberry
}

\author{
Babu R. Panthi ${ }^{1,2, *}$, Justin M. Renkema ${ }^{1,3}$, Sriyanka Lahiri ${ }^{1}$ and Oscar E. Liburd ${ }^{4}$ (D) \\ 1 Gulf Coast Research and Education Center, University of Florida, Wimauma, FL 33598, USA; \\ justin.Renkema@canada.ca (J.M.R.); lahiris@ufl.edu (S.L.) \\ 2 Crop and Soil Science Department, Oregon State University, Corvallis, OR 97331, USA \\ 3 London Research and Development Centre-Vineland Campus, Agriculture and Agri-Food Canada, \\ Vineland, ON LOR 2E0, Canada \\ 4 Department of Entomology and Nematology, University of Florida, Gainesville, FL 32611, USA; \\ oeliburd@ufl.edu \\ * Correspondence: babu.panthi@oregonstate.edu
}

check for updates

Citation: Panthi, B.R.; Renkema, J.M.; Lahiri, S.; Liburd, O.E.

Spatio-Temporal Distribution and Fixed-Precision Sampling Plan of Scirtothrips dorsalis (Thysanoptera: Thripidae) in Florida Blueberry. Insects 2021, 12, 256. https:// doi.org/10.3390/insects12030256

Academic Editor: Grzegorz A. Buczkowski

Received: 24 February 2021

Accepted: 15 March 2021

Published: 18 March 2021

Publisher's Note: MDPI stays neutral with regard to jurisdictional claims in published maps and institutional affiliations.

Copyright: (c) 2021 by the authors. Licensee MDPI, Basel, Switzerland. This article is an open access article distributed under the terms and conditions of the Creative Commons Attribution (CC BY) license (https:/ / creativecommons.org/licenses/by/ $4.0 /)$.
Simple Summary: Scirtothrips dorsalis, chilli thrips, is an invasive insect species in Florida and an important foliar pest of blueberry. Sound knowledge of insect distribution within the field is needed to formulate accurate sampling methods. Fourteen blueberry fields were systematically sampled for chilli thrips during the summers of 2017 and 2018. Field counts were modeled in various spatial models and determined chilli thrips had temporally stable aggregated distribution. A fixed-precision sampling plan was developed for summer sampling, requiring seven and three sampling units (sampling unit $=10$ young blueberry shoots) to estimate a nominal mean density of 20 chilli thrips with a precision of $25 \%$ and $40 \%$, respectively. The sampling plan can be used to improve the timing of control measures and assess the effectiveness of these control measures.

Abstract: Scirtothrips dorsalis Hood is an invasive and foliar pest of Florida blueberry that reduces plant growth by feeding on new leaf growth. A sampling plan is needed to make informed control decisions for $S$. dorsalis in blueberry. Fourteen blueberry fields in central Florida were surveyed in 2017 and 2018 after summer pruning to determine the spatial and temporal distribution of $S$. dorsalis and to develop a fixed-precision sampling plan. A sampling unit of ten blueberry shoots (with four to five leaves each) was collected from one blueberry bush at each point along a $40 \times 40 \mathrm{~m}$ grid. Field counts of $S$. dorsalis varied largely ranging from zero to 1122 adults and larvae per sampling unit. Scirtothrips dorsalis had aggregated distribution that was consistent within fields and temporally stable between summers, according to Taylor's power law (TPL) (aggregation parameter, $b=1.57$ ), probability distributions (56 out of 70 sampling occasions fit the negative binomial distribution), Lloyd's index ( $b>1$ in 94\% occasions), and Spatial Analysis by Distance IndicEs ( $31 \%$ had significant clusters). The newly developed fixed-precision sampling plan required 167, 42, seven, or three sampling units to estimate a nominal mean density of $20 \mathrm{~S}$. dorsalis per sampling unit with a precision of $5 \%, 10 \%, 25 \%$, or $40 \%$, respectively. New knowledge on $S$. dorsalis distribution will aid in evaluating the timing and effectiveness of control measures.

Keywords: chilli thrips; invasive pest; spatial analysis; aggregation indices; monitoring

\section{Introduction}

Scirtothrips dorsalis Hood (Thysanoptera: Thripidae) is invasive to the United States [1], as it was accidentally introduced from South Asia and became established in south Florida in 2005 in Knock Out ${ }^{\circledR}$ rose plants (Rosa X 'Radrazz': Rosaceae) [2]. Since then, S. dorsalis has become a pest of vegetable, ornamental, and fruits crops, and minor pest of landscape plants 
in Florida and Texas [1,3-7]. It has also been reported in other southern US states including Louisiana, Georgia, Alabama, Mississippi, and South Carolina, with a potential to expand up to western and northeastern US states and southern Canada [1,8,9]. In Florida, S. dorsalis is a significant pest of pepper (Capsicum spp., Solanaceae) [10], rose [11], strawberry (Fragaria $\times$ ananassa Duchesne, Rosaceae) [12], blueberry (Vaccinium sp., Ericaceae) [13], and landscape plants [5]. Scirtothrips dorsalis is minute (1-2 mm long) with yellow-colored body, dark-fringed wings, and dark stripes on dorso-abdominal segments [14]. Adult females live for $18-25$ days at $25^{\circ} \mathrm{C}$ and oviposit 40-50 kidney-shaped eggs underneath leaf tissues [15]. Larvae with transparent white bodies eclose in 67 days and complete two actively feeding instars in 4-6 days at $25^{\circ} \mathrm{C}$ [16]. Two inactive pupal stages complete development either on leaf, leaf litter, or soil in $2-3$ days at $25^{\circ} \mathrm{C}$ [4]. Both adults and larvae cause injury to new leaf growth by removing cellular contents from leaf tissues using piercing and sucking type mouthparts.

Scirtothrips dorsalis occurs year-round in perennial blueberry in Florida and is abundant on new leaf growth after summer pruning [4]. Feeding injury on blueberry plants first appears as bronzing along leaf veins and blades, and heavy S. dorsalis infestation causes upward leaf curl and distortion [4]. Hot and humid summers favor rapid population growth of $S$. dorsalis, leading to a reduction of blueberry growth. Insecticides are routinely applied to control S. dorsalis in conventional fields [13], although other ecofriendly control measures are available such as mycoinsecticides and biological control agents [1]. Insecticides are usually applied every two weeks (B. Panthi pers. comm.), as the highly effective insecticide, spinetoram, has a residual activity for about two weeks [13]. When insecticides with the same mode of action are applied repeatedly, there is increased selection pressure for thrips populations to develop resistance [17]. Scirtothrips dorsalis has developed resistance to monocrotophos, acephate, dimethoate, phosalone, carbaryl, and triazophos in India [17]. In another study, S. dorsalis showed no or very low level of resistance against organophosphates (acephate, chlorpyrifos, quinalphos, and dimethoate), neonicotinoids (thiamethoxam, imidacloprid), and abamectin as measured by resistance ratio (RR) but showed 21-28 fold increase in RR to Spinosad 45SC probably due to multiple applications [18]. Moreover, frequent insecticide applications negatively affect non-target organisms that help to regulate thrips populations in blueberry plantings $[19,20]$. Thus, for sustainable management of $S$. dorsalis, insecticides should be judiciously applied.

Sampling plans are important tools for integrated pest management as they improve the decision-making process by accurately estimating the pest population in the field [21] so that unnecessary insecticide applications are avoided. Use of these plans typically requires fewer samples and thus less time to estimate pest populations compared to whole field scouting [21]. In addition, such tools can be used to evaluate the effectiveness of control measures $[10,11,22]$. A prerequisite of a sampling plan is the determination of the field spatial distribution of a pest by systematically sampling the pest [23]. Field pest counts can then be modeled in spatial and non-spatial models to determine the distribution parameters and aggregation indices specific to a pest in a given crop [23]. Finally, the distribution parameters can be modeled with mathematical equations to calculate the number of sampling units required to estimate a pest's mean field density [23]. Sampling plans of $S$. dorsalis have been developed for pepper and rose, by systematically collecting young leaf samples, counting the number of $S$. dorsalis per sampling unit, and calculating and modeling the distribution parameters $[10,11,22]$. However, since the distribution parameters and aggregation indices of an insect species vary between crops, the number of sampling units required to estimate the mean density changes by crop [23]. The information on the distribution patterns of $S$. dorsalis is lacking for Florida blueberry. Therefore, there is a considerable opportunity to improve the monitoring and decision of $S$. dorsalis in blueberry fields. The objectives of this study were to determine the spatial and temporal distribution of $S$. dorsalis in blueberry fields and to develop a fixed-precision sampling plan. 


\section{Materials and Methods}

\subsection{Field Surveys}

Fourteen southern highbush blueberry fields were surveyed from Jun to Sep in 2017 and 2018 in central Florida to assess the spatial and temporal distribution of $S$. dorsalis (Table 1). All but one field had one or two cultivars (Table 1). Growers pruned lateral shoots about two weeks before we first sampled, and most fields received two or three applications of insecticides during the summers (Table 2). A few growers were unwilling to share pruning and insecticide information and so information of only eight fields are presented in Table 2. Ten young blueberry shoots (four or five leaves each) were collected from one blueberry bush as one sampling unit per grid point along $40 \times 40 \mathrm{~m}$ grids in every field. The first grid point in each field was $1.5 \mathrm{~m}$ from the edges near a field corner; its GPS coordinates were recorded. Due to variable field sizes (1.6-5.9 ha), the number of sampling units varied from 18 to 45 per field. Each field was sampled three times each year, with intervals of at least 25 days. Sampling occurred during the morning hours (900-1100 h) when $S$. dorsalis activity was low [24]. Leaf samples were placed in labeled plastic sealed bags $\left(15 \times 12 \mathrm{~cm}\right.$, Ziploc ${ }^{\circledR}$, S.C. Johnson and Son, Inc., Racine, WI, USA) and brought back to the laboratory. Two hundred and fifty $\mathrm{mL}$ of $70 \%$ ethanol was poured into the bag. Leaf samples were rinsed by manually shaking the bag for two minutes and the solution was poured into a $500 \mathrm{~mL}$ volume plastic container. The leaves were further rinsed, the solution with $S$. dorsalis was poured through a 160 -micron mesh cloth, and the filtrate with $S$. dorsalis was transferred onto a $10 \times 10 \mathrm{~cm}$ gridded petri-dish (FB0875711A, Fisherbrand ${ }^{\mathrm{TM}}$, Thermo Fisher Scientific, Waltham, MA, USA). The Petri dish with the filtrate was then observed under a stereomicroscope (LEICA LED3000 SLI, Leica Microsystems Inc, Wetzlar, Germany) at $25 \times$ magnification, and both stages of $S$. dorsalis were identified [25]. 


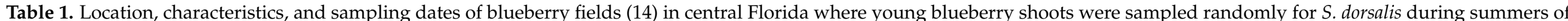
2017 and 2018

\begin{tabular}{|c|c|c|c|c|c|c|c|c|c|c|c|c|}
\hline \multirow{2}{*}{ Field } & \multicolumn{2}{|c|}{ GPS Coordinates } & \multirow{2}{*}{$\begin{array}{l}\text { Florida } \\
\text { County }\end{array}$} & \multirow{2}{*}{$\begin{array}{c}\text { No. of } \\
\text { Samples }\end{array}$} & \multirow{2}{*}{$\begin{array}{l}\text { Field Area } \\
\text { (ha) }\end{array}$} & \multirow{2}{*}{ Cultivars } & \multicolumn{3}{|c|}{2017 Sample Dates } & \multicolumn{3}{|c|}{2018 Sample Dates } \\
\hline & Latitude & Longitude & & & & & 1st & 2nd & 3rd & 1st & 2nd & 3rd \\
\hline $\mathrm{A}$ & 27.95216 & -82.15062 & Hillsborough & 23 & 2.4 & mdl, jwl & 20 June & 24 July & 30 August & 20 June & 24 July & 27 August \\
\hline B & 27.95217 & -82.13344 & Hillsborough & 37 & 3.5 & $\begin{array}{l}\text { ksr, ckd, } \\
\text { sph }\end{array}$ & 20 June & 1 August & 31 August & 20 June & 24 July & 27 August \\
\hline C & 27.95160 & -82.12887 & Hillsborough & 41 & 4.8 & fth & 21 June & 27 July & 31 August & 27 June & 26 July & 27 August \\
\hline $\mathrm{D}$ & 27.94213 & -82.14359 & Hillsborough & 45 & 5.9 & ckd & 21 June & 24 July & 30 August & 27 June & 26 July & 27 August \\
\hline $\mathrm{E}$ & 27.73754 & -82.22836 & Hillsborough & 40 & 4.7 & ksr & 22 June & 26 July & 29 August & 22 June & 27 July & 14 September \\
\hline $\mathrm{F}$ & 27.74114 & -82.23246 & Hillsborough & 30 & 3.5 & vnt, fth & 22 June & 26 July & 29 August & 22 June & 27 July & 14 September \\
\hline $\mathrm{H}$ & 28.75730 & -82.27129 & Citrus & 30 & 3.1 & emr & 19 June & 26 July & $x$ & 3 July & 3 August & 5 September \\
\hline I & 28.42770 & -81.78181 & Lake & 30 & 2.8 & emr & 19 June & 28 July & 30 August & 3 July & 3 August & 5 September \\
\hline $\mathrm{J}$ & 28.44823 & -81.68027 & Lake & 30 & 2.9 & $\mathrm{emr}$ & 20 June & 31 July & 30 August & $\mathrm{x}$ & $x$ & $\mathrm{x}$ \\
\hline $\mathrm{K}$ & 28.38861 & -82.34166 & Pasco & 40 & 4.7 & emr & 27 June & 2 August & $\mathrm{x}$ & $\mathrm{x}$ & $\mathrm{x}$ & $\mathrm{x}$ \\
\hline $\mathrm{L}$ & 28.44956 & -82.34541 & Hernando & 35 & 4.2 & emr & 30 June & 26 July & 30 August & 3 July & 3 August & 5 September \\
\hline $\mathrm{M}$ & 27.69529 & -82.15803 & Hillsborough & 31 & 2.9 & jwl, emr & $x$ & $\mathrm{x}$ & $\mathrm{x}$ & 5 July & 24 July & 14 September \\
\hline $\mathrm{N}$ & 28.74367 & -82.27950 & Citrus & 25 & 3.0 & swt & $x$ & $x$ & $x$ & 3 July & 3 August & 5 September \\
\hline
\end{tabular}

Cultivar abbreviations: $\mathrm{mdl}=$ Meadowlark, jwl $=$ Jewel, $\mathrm{emr}=$ Emerald, $\mathrm{ksr}=$ Kestrel, $\mathrm{ckd}=$ Chickadee, $\mathrm{sph}=$ Spring High, $\mathrm{fth}=$ Farthing, $\mathrm{vnt}=$ Ventura, swt $=$ Sweet Crisp. $(\mathrm{x})$ information not available

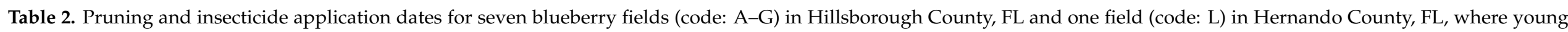
blueberry shoots were sampled to assess the distribution of $S$. dorsalis during summers of 2017 and 2018.

\begin{tabular}{|c|c|c|c|c|c|c|c|c|c|c|c|c|c|c|}
\hline \multirow{4}{*}{$\begin{array}{c}\begin{array}{c}\text { Field } \\
\text { Code }\end{array} \\
\text { A }\end{array}$} & \multicolumn{2}{|c|}{ Pruning Dates } & \multicolumn{12}{|c|}{ Insecticide Application Dates } \\
\hline & \multirow{2}{*}{2017} & \multirow{2}{*}{2018} & \multicolumn{6}{|c|}{2017} & \multicolumn{6}{|c|}{2018} \\
\hline & & & \multicolumn{2}{|c|}{ 1st } & \multicolumn{2}{|c|}{ 2nd } & \multicolumn{2}{|c|}{ 3rd } & \multicolumn{2}{|c|}{ 1st } & \multicolumn{2}{|c|}{ 2nd } & \multicolumn{2}{|c|}{ 3rd } \\
\hline & 12 June & 6 June & $*$ & & 27 July & fen $t$ & 21 August & fen & 13 June & суа & 27 July & суа & 18 August & kao \\
\hline C & 30 May & 1 June & 1 July & cya & 15 August & mal & 30 August & $\mathrm{mal}$ & 1 July & суа & - & & - & \\
\hline $\mathrm{D}$ & 15 May & 18 May & 7 June & spi & 17 July & spi & * & & 14 June & ace & 14 July & ace & 6 August & bif \\
\hline E & 1 June & 1 June & 1 July & cya & 15 August & mal & 30 August & mal & 1 July & cya & $*$ & & 18 August & spi \\
\hline $\mathrm{F}$ & 1 June & 1 June & 1 July & cya & 15 August & mal & 30 August & mal & 1 July & cya & * & & 18 August & spi \\
\hline $\mathrm{G}$ & 30 May & 30 May & 4 July & spi + nov & 8 July & bif & 20 August & spi + ace & 2 July & spi + ace & * & & - & \\
\hline
\end{tabular}

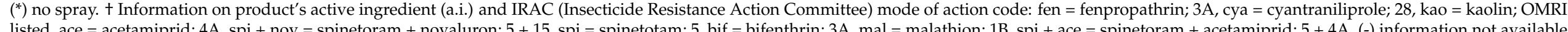




\subsection{Statistical Analysis}

The location of grid points of each field was categorized as either 'inside of the field' or 'field edge' and grid points designated as 'field edge' were subcategorized as adjacent to 'vegetation space' or 'open space'. Then, the probability of $S$. dorsalis occurring in each category was assessed with contingency tables, using the likelihood ratio tests. Data were $\log (x+1)$ transformed to normalize the error variance. Tukey's honest significance test was used as a post-hoc mean separation at $P=0.05$, and the back-transformed means and $95 \%$ confidence intervals are presented. Analyses were made using JMP ${ }^{\circledR}$ Pro 15.0.0 (SAS Institute Inc., Cary, NC, USA).

\subsection{Spatial Analysis}

Field means and variances of $S$. dorsalis counts were modeled in Taylor's power law (TPL) using the power law function. Taylor's power law relates variance $\left(\sigma^{2}\right)$ of counts per unit area to the corresponding mean $(\mu)$ by a power law such that,

$$
\sigma^{2}=a \mu^{b}
$$

where $a$ is a sampling factor and $b$ is an aggregation parameter. The relationship is linearized as,

$$
\log (V)=\log (a)+b^{*} \log (M)
$$

where the sample mean $(M)$ approximates the population mean $(\mu)$, the sample variance $(V)$ approximates the population variance $\left(\sigma^{2}\right), \log (a)$ is the intercept, and $b$ is the slope or the aggregation parameter. The distribution is considered random if $b=1$, regular if $b<1$, and aggregated if $b>1$. Field counts were also fit to the Poisson distribution and Negative binomial distribution using the fit_two_distr function, and data were considered to belong to a frequency distribution when the observed and expected frequencies were not different (Chi-square test at $p>0.05$ ). The function sadie was used to calculate the index of SADIE (Spatial Analysis of Distance Indices) index, $I_{a}$, which indicates significant clustering if the index is greater than $1.5[26,27]$. Lloyd's patchiness index, $P$, was determined using the function agg index, and the degree of patchiness increases as the index becomes greater than the unity. The R-package epiphy was used for all the spatial analyses using R, version 3.5.1. Correlations between aggregation indices $\left(I_{a}, k\right.$, and $\left.P\right)$, sampling dates within and between years, and field means were determined through multivariate analysis in JMP ${ }^{\circledR}$ Pro 15.0.0 (SAS Institute Inc. 2018).

\subsection{Sampling Plan}

To calculate a fixed-precision sampling plan, TPL parameters $(a$ and $b$ ) were modeled in Equation (1) for each $S$. dorsalis mean density, $\mathrm{m}$. Then, the number of sampling units (n) required to estimate a range of mean densities with $5 \%, 10 \%, 25 \%$, and $40 \%$ coefficient of variation $(\mathrm{CV})$ was calculated by inserting $v$ and $m$ in Equation (3) described by Binns et al. [23]:

$$
n=v\left(\frac{1}{\mathrm{~m} * C V}\right)^{2}
$$

\section{Results}

\subsection{Field Surveys}

From 70 sampling occasions, a total of 35,631 S. dorsalis were sampled of which 23,818 were larvae and 11,813 were adults. The number of $S$. dorsalis ranged from 0-857 larvae and 0-442 adults per sampling unit with a mean of 10.4 larvae and 5.2 adults per field per sampling unit. Among 2282 sampling units, $46 \%$ had one to ten S. dorsalis, $25 \%$ had no S. dorsalis, $24 \%$ had $10-50$ S. dorsalis, and 5\% had 50-1122 S. dorsalis per sampling unit (Figure 1). Among 70 sampling occasions, $19 \%$ had field means of zero to one $S$. dorsalis, $66 \%$ had field means of one to $20 \mathrm{~S}$. dorsalis, $13 \%$ had field means of 20-60 S. dorsalis, and $1 \%$ had field means of 60-333 S. dorsalis. The field ' $\mathrm{I}$ ' had the highest mean density of $333 \mathrm{~S}$. 
dorsalis per sampling unit with counts up to $1122 \mathrm{~S}$. dorsalis per sampling unit during the second and third sampling date in 2018.

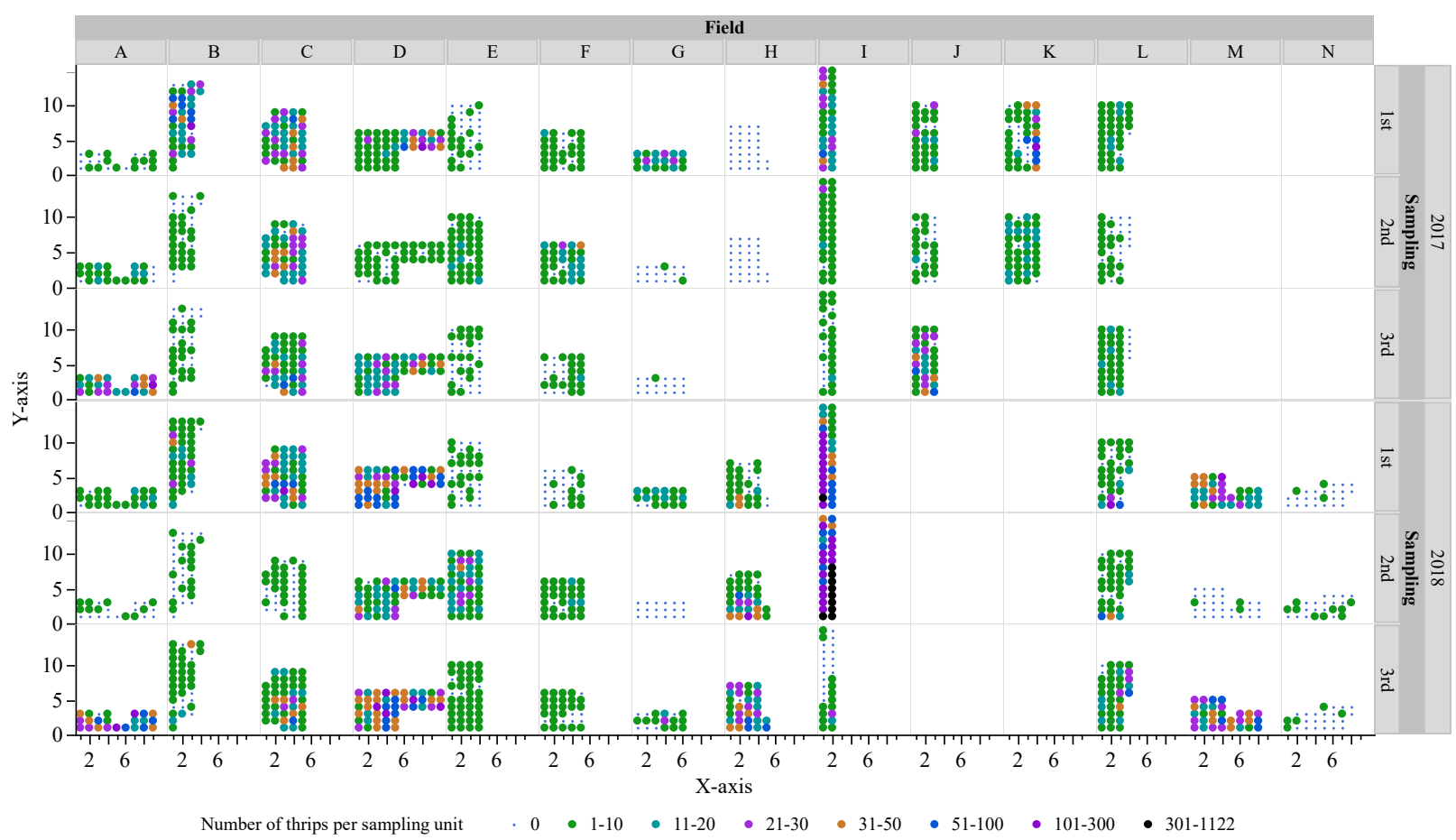

Figure 1. Field counts of Scirtothrips dorsalis per sampling unit (ten blueberry shoots) collected from fourteen blueberry fields in central Florida during summers of 2017 and 2018. Each dot represents a blueberry bush (one sampling unit) in $40 \times 40$ m grids.

The likelihood ratio test showed S. dorsalis occurred equally on the field edge (53\%) or inside of the field (47\%) (Table 3). However, when tested (likelihood ratio test) among those occurring along field edges, there were more $S$. dorsalis near open spaces $(64 \%)$ than near surrounding vegetation (36\%) (Table 3 ).

Table 3. Occurrences of $S$. dorsalis on blueberry plantings, inside of field or near field edges and with open space or surrounding vegetation, in central Florida during the summers (June-September) of 2017 and 2018.

\begin{tabular}{ccccc}
\hline \multirow{2}{*}{ Occurrence } & \multicolumn{2}{c}{ Location } & \multicolumn{2}{c}{ Field Edge } \\
\cline { 2 - 5 } & Inside of Field & Field Edge & Open Space & Surrounding Vegetation \\
\hline No (=0 S. dorsalis) & 248 & 315 & 170 & 145 \\
\hline Yes (>0 S. dorsalis) & 828 & 891 & 598 & 293 \\
\hline Likelihood ratio test & Chi-square $=2.9, p=0.089$ & \multicolumn{2}{c}{ Chi-square $=17.07, p<0.001$} \\
\hline
\end{tabular}

\subsection{Spatial Analysis}

Variances and means were significantly related as shown by Taylor's power law $\left(r^{2}=0.93, p<0.0001, a=1.50, b=1.57\right)$, indicating an aggregated distribution of $S$. dorsalis in blueberry fields (Figure 2). Fifty-six out of 70 sampling occasions fit the NBD, three fit the Poisson distribution, four fit both, and seven fit neither distribution (Chi-square test: $p>0.05$ ). For counts that fit the NBD, 46 had $k$ values below two, indicating highly aggregated populations (Figure $3 a$ ). Twenty-two out of 70 sampling occasions had SADIE indices greater than 1.5 (Figure $3 \mathrm{~b}$ ). A significant positive correlation between the SADIE index and field means $\left(r^{2}=0.56, p<0.0001\right)$ showed that the clustering of $S$. dorsalis increased with the $S$. dorsalis field mean density. Sixty-eight out of 70 sampling occasions had Lloyd's index greater than the unity, indicating significant patches of $S$. dorsalis populations 
(Figure 3c). Non-significant correlations between aggregation indices $\left(k, I_{a}\right.$, and $\left.P\right)$ and sampling dates within year $\left(k: r^{2}=-0.002, p=0.98 ; I_{a}: r^{2}=0.06, p=0.61\right.$; and $P: r^{2}=-0.05$, $p=0.69)$ and between years $\left(k: r^{2}=0.03, p=0.83 ; I_{a}: r^{2}=0.01, p=0.93\right.$; and $P: r^{2}=0.16$, $p=0.19$ ) showed that the $S$. dorsalis distribution was temporally stable within fields and between seasons, respectively. The field mean density of $S$. dorsalis also did not change with sampling dates within the same year $\left(r^{2}=-0.03, p=0.8\right)$ and between the two years $\left(r^{2}=0.19, p=0.11\right)$.

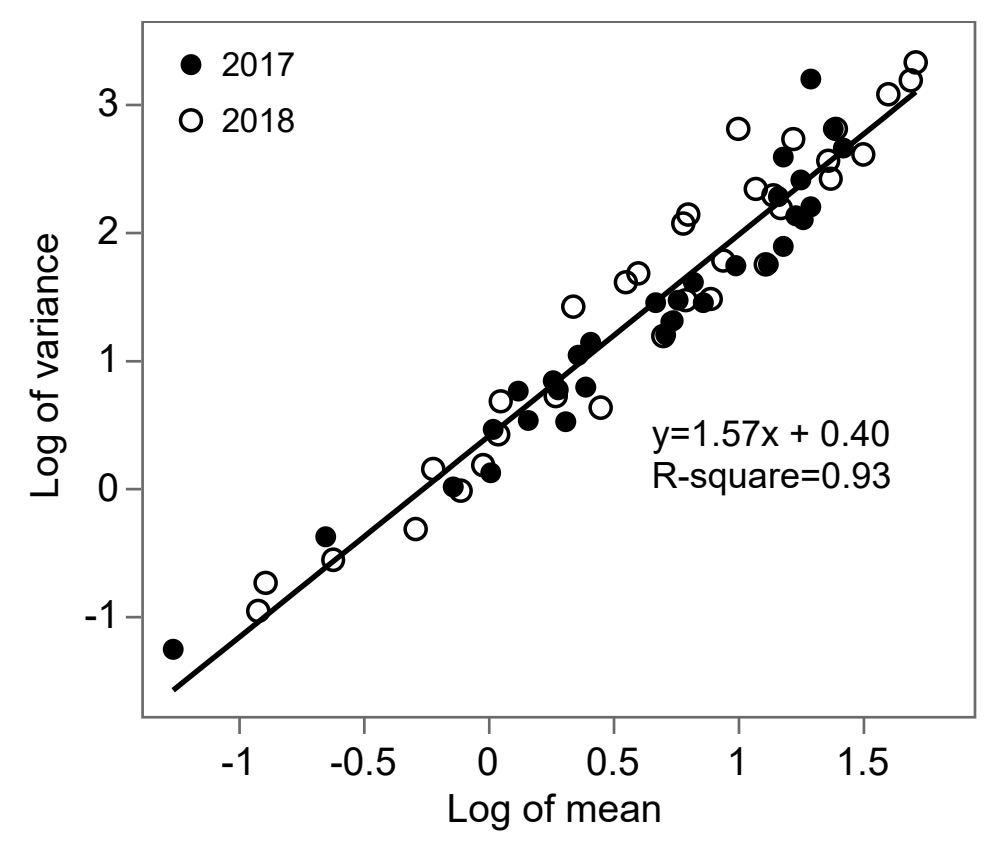

Figure 2. Linear relationship between field variances and means $(n=70)$ of $S$. dorsalis counts from leaf samples collected from fourteen blueberry fields in central Florida during summers of 2017 and 2018.

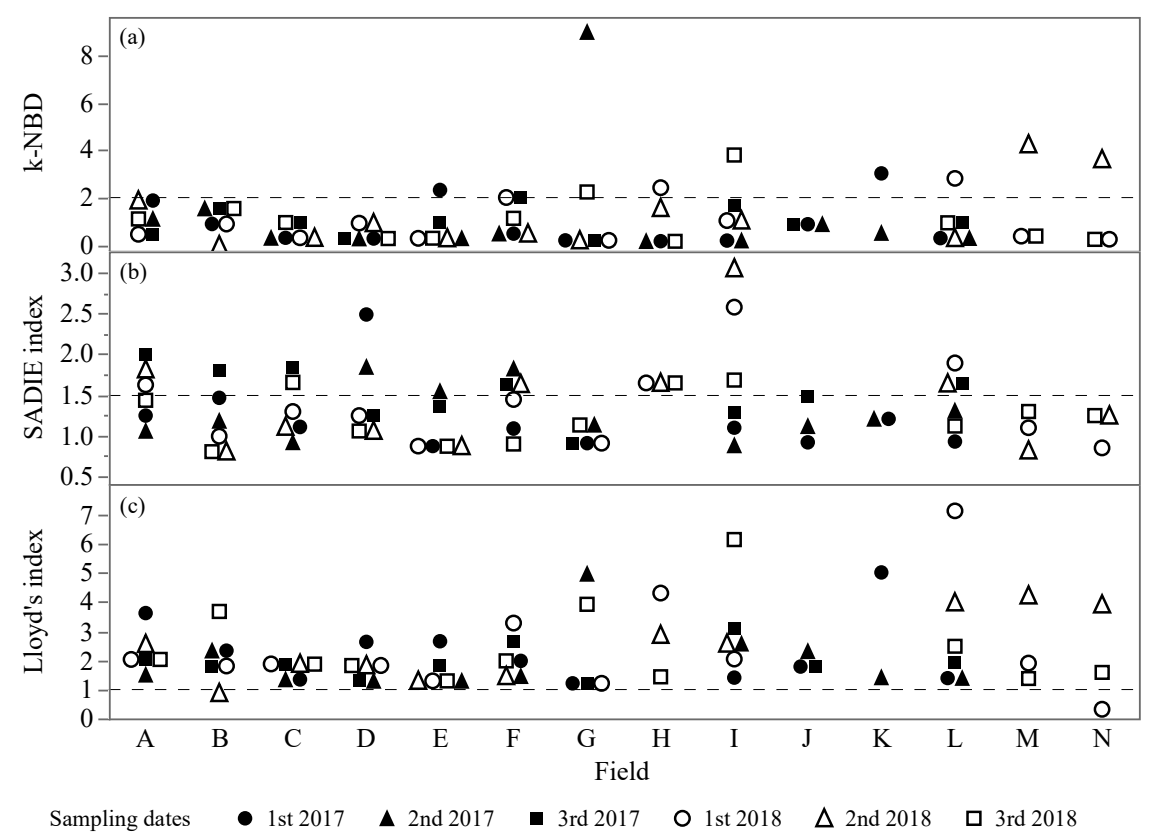

Figure 3. Aggregation indices from adult and larval S. dorsalis count on leaf samples in fourteen blueberry fields in central Florida during the summers of 2017 and 2018. Dashed lines are the break-even points of aggregation indices; the distribution of the counts is aggregated if (a) k-NBD (Negative Binomial Distribution) $<2$, (b) SADIE (Spatial Analysis of Distance Indices) index $>1.5$, and (c) Lloyd's index $>1$. 


\subsection{Fixed-Precision Sampling Plan}

The number of sampling units required to estimate the $S$. dorsalis population decreased as $\mathrm{CV}$ and/or mean density increased (Figure 4). According to the fixed-precision sampling plan, it would require 167,42 , seven, or three sampling units to estimate a nominal mean density of $20 \mathrm{~S}$. dorsalis per sampling unit with a CV of $5 \%, 10 \%, 25 \%$, or $40 \%$, respectively. Although sampling units can be calculated for any precision level by solving the equation provided in Figure 4, the figure only presents sampling plans for $25 \%$ and $40 \%$ precisions for a clear figure.

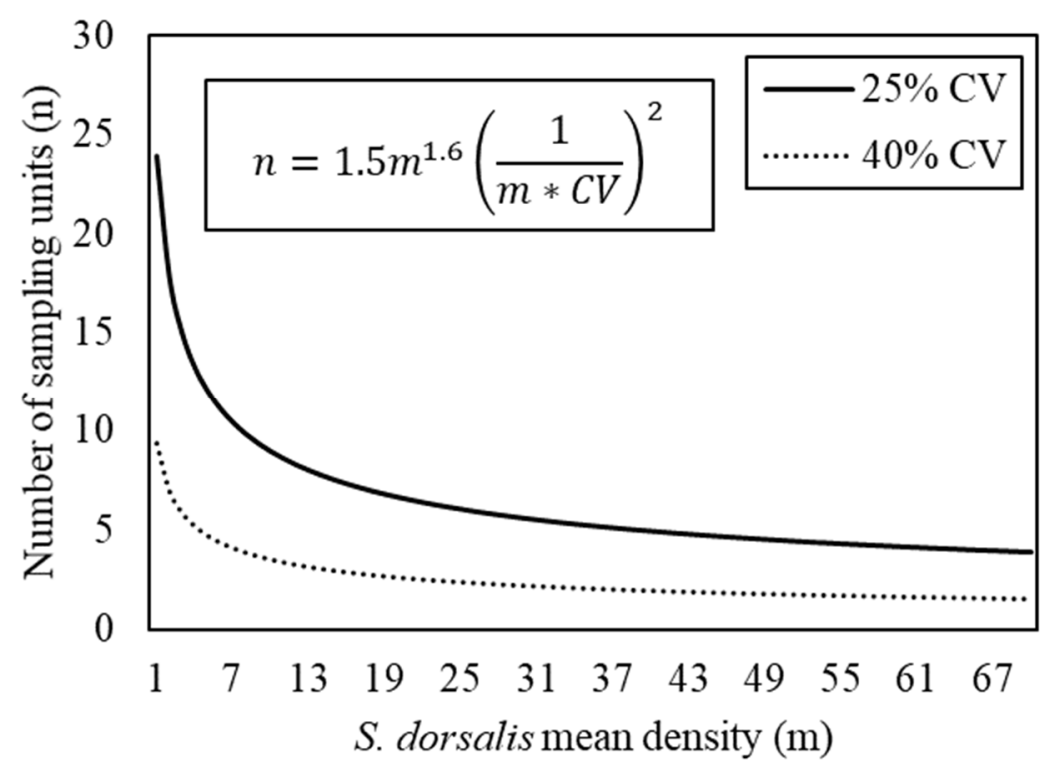

Figure 4. Number of sampling units $(n)$ required to estimate the $S$. dorsalis mean density $(m)$ in Florida blueberry fields with variable coefficients of variation $(C V)$ calculated by modeling Taylor's power law parameters into the mathematical formula: $n=\mathrm{a} * \mathrm{~m}^{b}(1 / m * C V)^{2}$.

\section{Discussion}

This is the first study to characterize the spatial and temporal distribution of $S$. dorsalis in blueberry fields in Florida. Spatial and non-spatial models fit to the data showed a consistent aggregated distribution of $S$. dorsalis in blueberry fields. The distribution of $S$. dorsalis in particular fields was stable between seasons, allowing sampling plans to be used throughout the season in blueberry fields. The fixed-precision sampling plan developed as a result of characterizing the field distribution of $S$. dorsalis requires three and seven sampling units (one sampling unit $=10$ blueberry shoots) to estimate a nominal mean density of $20 \mathrm{~S}$. dorsalis per sampling unit (two S. dorsalis per blueberry shoot) with a precision of $25 \%$ and $40 \%$, respectively. In other crops affected by S. dorsalis, seven or nine leaf samples were required to estimate a mean density of one $S$. dorsalis in rose with a precision of $25 \%$ and two $S$. dorsalis in pepper with a precision of $10 \%$, respectively $[10,11]$. Sampling for $S$. dorsalis along blueberry field edges next to open space will maximize the accuracy of the sampling plan since more $S$. dorsalis were found at edge locations next to open than vegetated space.

The aggregated distribution of $S$. dorsalis in blueberry fields is likely due to minimal movement of S. dorsalis among blueberry bushes [25]. Scirtothrips dorsalis showed similar behavior in strawberry where adults moved slowly between strawberry plants and were aggregated in strawberry fields [25]. The aggregated behavior of $S$. dorsalis was also observed in pepper fields [10] and potted rose plants [24]. The slow movement and aggregation of $S$. dorsalis are likely to be due to aggregation pheromones as in other thrips, Frankliniella occidentalis (Pergande), and Thrips palmi Karny (Thripidae) [28]. Therefore, there is an opportunity to test for the presence and potency of the sex pheromone of 
S. dorsalis to advance the knowledge of $S$. dorsalis biology and develop potential pest management techniques such as mass trapping.

In this study, as mean density increased, the area of S. dorsalis clusters (SADIE index) increased, which is likely due to outward movement of $S$. dorsalis from the initial point of infestation [29]. However, a significant increase in the cluster area was found only when the mean density was higher than $50 \mathrm{~S}$. dorsalis per ten blueberry shoots. Assuming that plants with defoliated blueberry leaves become poor hosts for adult and larval thrips, enhanced movement of adults in response to a deterioration of blueberry shoots is expected to increase their lifetime reproductive success. However, since the quantity and nutritional quality of healthy and defoliated leaves as food resources was not assessed in this study, this hypothesis remains to be tested experimentally. Future studies should focus on evaluating whether and to what extent aggregations of $S$. dorsalis on host plants affect the survivorship and fecundity of $S$. dorsalis.

Blueberries in Florida are pruned during summer after harvest to promote new growth. Summer pruning may disrupt $S$. dorsalis populations in blueberry and reduce population build-up. We did not test the effect of pruning timing; however, future studies should test whether delayed pruning could reduce the impact of $S$. dorsalis in blueberry. In addition, the shoots infested with $S$. dorsalis moved to healthy shoots of grapes in Japan [30]. Therefore, the pruned shoots should be properly disposed of to reduce further infestations as $S$. dorsalis might disperse out from the pruned and defoliated leaves.

For estimating S. dorsalis populations in blueberry fields, we recommend collecting ten young blueberry shoots per bush (=one sampling unit) and counting all larvae and adults. Seven sampling units are required to estimate a nominal mean density of $20 \mathrm{~S}$. dorsalis per sampling unit with a precision of $25 \%$. A precision of $25 \%$ is acceptable in estimating mean densities of insects in the field, whereas a precision of $10 \%$ is acceptable for research purposes [23]. However, a lower precision of $40 \%$ is sufficient when estimating mean density to evaluate the insecticide efficacy. At a precision level of $40 \%$, just three sampling units are needed to estimate the mean density.

Numbers of sampling units required to estimate $S$. dorsalis mean density in blueberry varied from other crops such as strawberry, rose, and pepper, where $S$. dorsalis infested heavily on new leaf growths. The difference in the number of sampling units is likely related to how S. dorsalis is distributed among host plants. Thrips have aggregated distributions within fields, however, aggregation patterns vary among plant species because of how they distribute among plants. Such aggregations are characterized using aggregation indices such as slope parameter of TPL model, which increases with aggregation [31]. The TPL parameter ' $\mathrm{b}$ ' of $S$. dorsalis in blueberry was 1.57 and was 1.72 in strawberry, indicating a more aggregated population of $S$. dorsalis in strawberry than blueberry fields. A recent study showed that $S$. dorsalis move slowly between strawberry plants, causing the population to aggregate in initially infested plants. Similarly, the aggregation index in rose was 1.14 (lesser aggregation than in blueberry and strawberry), and it varied from 1.10 to 1.63 in pepper fields with respect to different plot sizes.

A fixed-precision sampling plan will allow the estimation of $S$. dorsalis populations with a manageable number of sampling units. Estimating a mean density of $20 \mathrm{~S}$. dorsalis per sampling unit would require $5 \mathrm{~min}$ to collect ten blueberry shoots and count the number of $S$. dorsalis in blueberry fields, for a total of $35 \mathrm{~min}$ to collect seven sampling units. Future research is needed to determine an economic threshold of $S$. dorsalis to make accurate control decisions to manage this pest in blueberry fields. An economic threshold requires a direct relationship between pest density and plant growth or yield. The $S$. dorsalis population levels in blueberry fields in the summer may not necessarily have a direct relationship to fruit harvests the following spring (April-May). However, S. dorsalis infestations over time can weaken bushes, reduce the growth, and ultimately affect the yield. Therefore, two thresholds and sequential sampling plans may be needed to time insecticide application, one to avoid injury during the summer when plants are young and a second pre-harvest threshold for older, bearing bushes to avoid yield losses. 


\section{Conclusions}

Scirtothrips dorsalis heavily infests new blueberry shoots after summer pruning and reduces plant growth by leaf defoliation. New knowledge on the distribution of $S$. dorsalis in fields resulting in improved sampling methods will enable better management decisions and more profitable blueberry production in Florida. However, management actions with insecticides should be timed in a way as not to disrupt the ecosystem services and only if the threshold is high enough to cause yield reduction.

Author Contributions: Conceptualization, J.M.R.; methodology, J.M.R. and B.R.P.; software, B.R.P.; validation, B.R.P. and J.M.R.; formal analysis, B.R.P.; investigation, B.R.P.; resources, J.M.R., S.L., and O.E.L.; data curation, B.R.P.; writing-original draft preparation, B.R.P.; writing-review and editing, B.R.P., J.M.R., S.L., and O.E.L.; visualization, B.R.P.; supervision, J.M.R. and S.L.; project administration, J.M.R.; funding acquisition, J.M.R., O.E.L., and S.L. All authors have read and agreed to the published version of the manuscript.

Funding: This research was funded by the Florida Specialty Crop Block Grant Program, grant number 024135, and in part by the USDA National Institute of Food and Agriculture Hatch Project No. FLA-GCR-005888.

Institutional Review Board Statement: Not applicable.

Data Availability Statement: Not applicable.

Acknowledgments: We are grateful to Marc Santos, Ryan Batts, Janine Spies, Amrit Chhetri, Mike Ayer, and Chastity Perry for the collection and processing of leaf samples. A big thanks to blueberry growers for letting us sample their fields.

Conflicts of Interest: The authors declare no conflict of interest. The funders had no role in the design of the study; in the collection, analyses, or interpretation of data; in the writing of the manuscript, or in the decision to publish the results.

\section{References}

1. Kumar, V.; Kakkar, G.; McKenzie, C.L.; Seal, D.R.; Osborne, L.S. An Overview of Chilli Thrips, Scirtothrips dorsalis (Thysanoptera: Thripidae) Biology, Distribution and Management. IntechOpen 2013. Available online: http://www.intechopen.com/books/ weed-and-pest-control-conventional-and-new-challenges/an-overview-of-chilli-thrips-scirtothrips-dorsalis-thysanopterathripidae-biology-distribution-and-m (accessed on 17 March 2021). [CrossRef]

2. Hodges, G.; Edwards, G.B.; Dixon, W. Chilli Thrips Scirtothrips dorsalis Hood (Thysanoptera: Thripidae) a New Pest Thrips for Florida; Florida Department of Agriculture and Consumer Service, Department of Primary Industries: St. Gainesville, FL, USA, 2005.

3. Panthi, B.; Renkema, J. Managing Scirtothrips dorsalis Hood (Thysanoptera: Thripidae) in Florida Strawberry with Flupyradifurone. Int. J. Fruit Sci. 2020, 1-11. [CrossRef]

4. Liburd, O.E.; Panthi, B.R.; Phillips, D.A. Chilli Thrips on Blueberries in Florida. EDIS 2020, 2020, 4. [CrossRef]

5. Dale, A.G.; Borden, M.A. Evaluation of Reduced-Risk Insecticides to Control Chilli Thrips (Thysanoptera: Thripidae) and Conserve Natural Enemies on Ornamental Plants. Fla. Entomol. 2018, 101, 237-243. [CrossRef]

6. Mannion, C.M.; Derksen, A.I.; Seal, D.R.; Osborne, L.S.; Martin, C.G. Population Dynamics of Scirtothrips dorsalis (Thysanoptera: Thripidae) and Other Thrips Species on Two Ornamental Host Plant Species in Southern Florida. Environ. Entomol. 2014, 43, 849-858. [CrossRef] [PubMed]

7. Seal, D.R.; Klassen, W.; Kumar, V. Biological Parameters of Scirtothrips dorsalis (Thysanoptera: Thripidae) on Selected Hosts. Environ. Entomol. 2010, 39, 1389-1398. [CrossRef]

8. Nietschke, B.S.; Borchert, D.M.; Magarey, R.D.; Ciomperlik, M.A. Climatological Potential for Scirtothrips dorsalis (Thysanoptera: Thripidae) Establishment in the United States. Fla. Entomol. 2008, 91, 79-86. [CrossRef]

9. Dickey, A.M.; Kumar, V.; Hoddle, M.S.; Funderburk, J.E.; Morgan, J.K.; Jara-Cavieres, A.; Shatters, R.G.J.; Osborne, L.S.; McKenzie, C.L. The Scirtothrips dorsalis Species Complex: Endemism and Invasion in a Global Pest. PLoS ONE 2015, 10, e0123747. [CrossRef]

10. Seal, D.R.; Ciomperlik, M.A.; Richards, M.L.; Klassen, W. Distribution of Chilli Thrips, Scirtothrips dorsalis (Thysanoptera: Thripidae), in Pepper Fields and Pepper Plants on St. Vincent. Fla. Entomol. 2006, 89, 311-320. [CrossRef]

11. Aristizábal, L.F.; Mascarin, G.M.; Cherry, R.H.; Chaves-Cordoba, B.; Arthurs, S.P. A Rapid Sampling Plan for Scirtothrips dorsalis (Thysanoptera: Thripidae) on Container Shrub Rose (Rosa 'Radrazz'). J. Econ. Entomol. 2016, 109, 2543-2550. [CrossRef]

12. Panthi, B.R.; Renkema, J.M.; Lahiri, S.; Liburd, O.E. The Short-Range Movement of Scirtothrips dorsalis (Thysanoptera: Thripidae) and Rate of Spread of Feeding Injury among Strawberry Plants. Environ. Entomol. 2020. [CrossRef]

13. Panthi, B.; Liburd, O.; Lahiri, S.; Rhodes, E. Efficacy Test of Various Insecticides to Control Scirtothrips dorsalis in Southern Highbush Blueberries. Arthropod Manag. Tests 2020, 45. [CrossRef] 
14. Kumar, V.; Seal, D.R.; Osborne, L.S.; McKenzie, C.L. Coupling Scanning Electron Microscopy with DNA Bar Coding: A Novel Approach for Thrips Identification. Appl. Entomol. Zool. 2014, 49, 403-409. [CrossRef]

15. Kang, S.H.; Lee, J.-H.; Kim, D.-S. Temperature-Dependent Fecundity of Overwintered Scirtothrips dorsalis (Thysanoptera: Thripidae) and Its Oviposition Model with Field Validation. Pest Manag. Sci. 2015, 71, 1441-1451. [CrossRef] [PubMed]

16. Tatara, A. Effect of Temperature and Host Plant on the Development, Fertility and Longevity of Scirtothrips dorsalis Hood (Thysanoptera: Thripidae). Appl. Entomol. Zool. 1994, 29, 31-37. [CrossRef]

17. Reddy, G.P.V.; Prasad, V.; Rao, R.S. Relative Resistance in Chilli Thrips, Scirtothrips dorsalis Hood Populations in Andhra Pradesh to Some Conventional Insecticides. Indian J. Plant Prot. 1992, 20, 218-222.

18. Rao, C.N.; George, A.; Rahangadale, S. Monitoring of Resistance in Field Populations of Scirtothrips dorsalis (Thysanoptera: Thripidae) and Diaphorina citri (Hemiptera: Liviidae) to Commonly Used Insecticides in Citrus in Central India. J. Econ. Entomol. 2019, 112, 324-328. [CrossRef]

19. James, D.; Price, T.S.; Wright, L.C.; Perez, J. Abundance and Phenology of Mites, Leafhoppers, and Thrips on Pesticide-Treated and Untreated Wine Grapes in Southcentral Washington. J. Agric. Urban Entomol. 2002, 19, 45-54.

20. Wang, Z.-H.; Gong, Y.-J.; Jin, G.-H.; Li, B.-Y.; Chen, J.-C.; Kang, Z.-J.; Zhu, L.; Gao, Y.-L.; Reitz, S.; Wei, S.-J. Field-Evolved Resistance to Insecticides in the Invasive Western Flower Thrips Frankliniella Occidentalis (Pergande) (Thysanoptera: Thripidae) in China. Pest Manag. Sci. 2016, 72, 1440-1444. [CrossRef]

21. Southwood, T.R.E.; Henderson, P.A. Ecological Methods, 4th ed.; John Wiley \& Sons: Hoboken, NJ, USA, 2016.

22. Aliakbarpour, H.; Salmah, M.R.C. Seasonal Abundance and Spatial Distribution of Larval and Adult Thrips (Thysanoptera) on Weed Host Plants in Mango Orchards in Penang, Malaysia. Appl. Entomol. Zool. 2011, 46, 185-194. [CrossRef]

23. Binns, M.R.; Nyrop, J.P.; van der Werf, W.; Werf, W. Sampling and Monitoring in Crop Protection: The Theoretical Basis for Developing Practical Decision Guides; CABI: Wallingford, UK, 2000.

24. Kumar, V.; Kakkar, G.; Seal, D.R.; McKenzie, C.L.; Colee, J.; Osborne, L.S. Temporal and Spatial Distribution of an Invasive Thrips Species Scirtothrips dorsalis (Thysanoptera: Thripidae). Crop Prot. 2014, 55, 80-90. [CrossRef]

25. Panthi, B. Ecology, Behavior, and Management of Scirtothrips dorsalis Hood in Florida Strawberry and Blueberry. Ph.D. Thesis, University of Florida, Gainesville, FL, USA, 2020.

26. Perry, J.N. Spatial Analysis by Distance Indices. J. Anim. Ecol. 1995, 64, 303-314. [CrossRef]

27. Winder, L.; Alexander, C.; Griffiths, G.; Holland, J.; Woolley, C.; Perry, J. Twenty Years and Counting with SADIE: Spatial Analysis by Distance Indices Software and Review of Its Adoption and Use. Rethink. Ecol. 2019, 4, 1-16. [CrossRef]

28. Kirk, W.D.J. The Aggregation Pheromones of Thrips (Thysanoptera) and Their Potential for Pest Management. Int. J. Trop. Insect Sci. 2017, 37, 41. [CrossRef]

29. Rhainds, M.; Shipp, L. Dispersal of Adult Western Flower Thrips (Thysanoptera: Thripidae) on Chrysanthemum Plants: Impact of Feeding-Induced Senescence of Inflorescences. Environ. Entomol. 2003, 32, 1056-1065. [CrossRef]

30. Shibao, M.; Tanaka, F.; Fujisaki, K.; Nakasuji, F. Effects of Lateral Shoot Cutting on Population Density of the Chillie Thrips, Scirtothrips dorsalis Hood (Thysanoptera: Thripidae) on Grape. Appl. Entomol. Zool. 1993, 28, 35-41. [CrossRef]

31. Taylor, L.R. Aggregation, Variance and the Mean. Nature 1961, 189, 732-735. [CrossRef] 